\title{
Evaluation of the effects of dexmedetomidine infusion on oxygenation and lung mechanics in morbidly obese patients with restrictive lung disease
}

Ahmed Hasanin *D, Kareem Taha, Bassant Abdelhamid, Ayman Abougabal, Mohamed Elsayad, Amira Refaie, Sarah Amin, Shaimaa Wahba, Heba Omar, Mohamed Maher Kamel, Yaser Abdelwahab and Shereen M. Amin

\begin{abstract}
Background: Dexmedetomidine infusion improves oxygenation and lung mechanics in patients with chronic obstructive lung disease; however, its effect in patients with restrictive lung disease has not been thoroughly investigated yet. The aim of this work was to evaluate the effects of dexmedetomidine infusion on oxygenation and lung mechanics in morbidly obese patients with restrictive lung disease.

Methods: Forty-two morbidly obese patients scheduled for bariatric surgery were included in the study. Patients were randomized to receive either dexmedetomidine infusion at a bolus dose of $1 \mathrm{mcg} / \mathrm{Kg}$ followed by infusion at $1 \mathrm{mcg} / \mathrm{Kg} /$ hour for $90 \mathrm{~min}$ (Dexmedetomidine group), or normal saline infusion (Control group). Both groups were compared with regard to: oxygenation $\left\{\mathrm{P} / \mathrm{F}\right.$ ratio: $\mathrm{PaO}_{2} /$ fraction of inspired oxygen $\left.\left(\mathrm{FiO}_{2}\right)\right\}$, lung compliance, dead space, plateau pressure, blood pressure, and heart rate.

Results: Dexmedetomidine group showed significant improvement of the $\mathrm{PaO}_{2} / \mathrm{FiO}_{2}$ ratio, and higher lung compliance compared to control group by the end of drug infusion. Dexmedetomidine group demonstrated decreased dead space, plateau pressure, blood pressure, and heart rate compared to control group by the end of drug infusion.
\end{abstract}

Conclusion: A 90-min dexmedetomidine infusion resulted in moderate improvement in oxygenation and lung mechanics in morbidly obese patients with restrictive lung disease.

Trial registration: clinicaltrials.gov: NCT02843698 on 20 July 2016.

Keywords: Dexmedetomidine, Morbidly obese, Oxygenation

\section{Background}

Dexmedetomidine is a selective $\alpha-2$ agonist with various clinical uses in both anesthesia and intensive care unit. In addition to its sedative and cardiovascular effects, dexmedetomidine has favourable respiratory effects in animals $[1,2]$, and in selected patient groups in humans. The effects of dexmedetomidine on oxygenation and lung mechanics had been investigated in obstructive lung disease. Dexmedetomidine decreased dead space and improved both lung compliance

\footnotetext{
* Correspondence: ahmedmohamedhasanin@gmail.com

Department of anesthesia and critical care medicine, Cairo university, 01 elsarayah street, Elmanyal, Cairo 11559, Egypt
}

and oxygenation in chronic obstructive pulmonary disease (COPD) patients undergoing lung cancer surgery [3].

In restrictive lung disease, the possible effect of dexmedetomidine was not well investigated in humans. In an animal model of experimental obesity, dexmedetomidine administration showed better morphological and functional lung characteristics compared to propofol [4]; thus, we hypothesized that a similar effect could be present in humans. Morbidly obese patients are characterized by the high prevalence of restrictive lung disease [5]; thus, we investigated the effects of dexmedetomidine infusion on oxygenation (P/F ratio) as well as lung mechanics (compliance and dead space) in a selected group

(c) The Author(s). 2018 Open Access This article is distributed under the terms of the Creative Commons Attribution 4.0 International License (http://creativecommons.org/licenses/by/4.0/), which permits unrestricted use, distribution, and 
of morbidly obese patients with restrictive lung disease, to find out the possible benefits of this drug on this population.

\section{Methods}

A randomized controlled double-blinded study was conducted in Cairo university hospital after institutional board review approval (N-12-2016) on 24 December 2016. The study was registered at clinical.trials.gov registry system on 20 July 2016 (NCT02843698). A written informed consent was obtained from participants before recruitment. Patients were randomized according to an online random number generator. Concealment was achieved using sealed opaque envelopes.

The study included 42 morbidly obese patients \{with body mass index (BMI) above $40 \mathrm{Kg} / \mathrm{m}^{2}$ \} with restrictive lung disease \{diagnosed by pulmonary function tests: forced vital capacity $(\mathrm{FVC})<70 \%\}$, scheduled for laparoscopic sleeve gastrectomy. Exclusion criteria were: heart failure, arrhythmias, severe liver or kidney impairment. Patients with forced expiratory volume in $1 \mathrm{sec}$ (FEV1)/ FVC $<70 \%$ were also excluded.

Upon arrival at the operating room, patients were pre-medicated with metoclopramide $(10 \mathrm{mg})$ and ranitidine $(50 \mathrm{mg})$. Basic monitors were applied \{electrocardiogram (ECG), non-invasive blood pressure monitor, capnography and pulse oximetry\}. Drug dosing was calculated using lean body weight for all drugs except neostigmine (Total body weight was used) [6]. LBW was calculated using James equation \{Men: (1.10 weight) (128 (weight/height) $\left.{ }^{2}\right\}$, \{Women: (1.07 weight) - (148 (weight/height $\left.)^{2}\right\}$ [6]. Anesthesia was induced by propofol $(2 \mathrm{mg} / \mathrm{Kg} \mathrm{LBW})$ and fentanyl $(2 \mu \mathrm{g} / \mathrm{Kg} \mathrm{LBW})$. After induction of anesthesia, endotracheal tube was inserted aided by rocuronium $(0.5 \mathrm{mg} / \mathrm{Kg} \mathrm{LBW})$. Anesthesia was maintained by isoflurane $(1-1.5 \%)$ and rocuronium $(0.1 \mathrm{mg} / \mathrm{Kg} / 40 \mathrm{~min})$ at $\mathrm{FiO}_{2}$ of $40 \%$. Intravenous paracetamol (2 g) and Ketorolac (40 mg) was administered before the end of surgery.

Patients were mechanically ventilated using Maquet (Flow-i) anesthesia machine. Our ventilatory management included: volume controlled ventilation, low tidal volume (6-8 $\mathrm{ml} / \mathrm{Kg} \mathrm{LBW})$, positive end expiratory pressure (PEEP) 8-10 $\mathrm{mmH}_{2} \mathrm{O}$, and respiratory rate adopted to maintain end-tidal $\mathrm{CO}_{2}$ between 30 and $35 \mathrm{mmHg}$ [7]. No recruitment manoeuvres were used in our patients.

Patients were randomly allocated into our double-blinded study using computer generated sequence into two groups: 1 - Dexmedetomidine group $(n=21)$ : received dexmedetomidine (Precedex, Hospira, Lake forest, IL, USA) in a dose of $(1 \mu \mathrm{g} / \mathrm{Kg} \mathrm{LBW})$ bolus 15 -min after endotracheal intubation, followed by $0.5 \mu \mathrm{g} / \mathrm{Kg} /$ hour continuous infusion for 90 min. 2- Control group $(n=21)$ : received $1 \mathrm{~mL}$ normal saline followed by continuous normal saline infusion for
90 min. The study drug was prepared and the infusion rate was calculated by a research assistant to ensure blinding of the investigator.

At the end of the operation, isoflurane was discontinued, residual neuromuscular block was reversed using neostigmine $(0.05 \mathrm{mg} / \mathrm{Kg})$ and atropine $(0.02 \mathrm{mg} / \mathrm{Kg})$, then patient was extubated. In the post anesthesia care unit (PACU), patient was monitored by basic monitors (pulse oximetry, non-invasive blood pressure monitor, and ECG). Patients with oxygen saturation less than $88 \%$ on 6-l oxygen mask were admitted to the intensive care unit.

Dynamic lung compliance was calculated using Maquet anesthesia machine as: tidal volume/ (peak airway pressure PEEP). Static lung compliance was calculated as: Tidal volume/ (plateau pressure - PEEP). Plateau pressure was calculated by increasing the end-inspiratory pause to $30-40 \%$. Physiological dead space was calculated by Hardman \& Aitkenhead equation [8]: $\mathrm{Vd} / \mathrm{Vt}=1.14 \quad\left(\mathrm{PaCO}_{2}-\mathrm{EtCO}_{2}\right) /$ $\mathrm{PaCO}_{2}-0.005$.

\section{Primary outcome}

Oxygenation by the end study drug infusion (assessed by P/F ratio: $\mathrm{PaO}_{2}$ /Fraction of inspired oxygen).

\section{Secondary outcomes}

- Intraoperative oxygenation, lung compliance (static and dynamic), dead space (Vd/VT), and $\mathrm{PaCO}_{2}$ (5 minutes after endotracheal intubation and positioning, at $45 \mathrm{~min}$, and at $90 \mathrm{~min}$ after starting drug infusion).

- Heart rate, Systolic blood pressure (SBP), diastolic blood pressure (DBP), and plateau airway pressure (At the baseline, then every $15 \mathrm{~min}$ for $2 \mathrm{~h}$ ).

- Demographic data (age - gender - BMI - smoking - comorbidities), operative data (surgical time intraoperative fluids - blood loss), the need for postoperative ICU, the need for postoperative mechanical ventilation, postoperative complications, and Pasero opioid-induced sedation scale [9].

- The change in each of P/F ratio and dynamic lung compliance $(\Delta \mathrm{P} / \mathrm{F}$ ratio: $\mathrm{P} / \mathrm{F}$ ratio by the end of the study drug infusion $-\mathrm{P} / \mathrm{F}$ ratio at the baseline, $\Delta$ compliance: dynamic lung compliance by the end of the study drug infusion - dynamic lung compliance at the baseline)

- $\Delta$ dead space (\%): dead space by the end of the study drug infusion - dead space at the baseline/ dead space by the end of the study drug infusion \%).

\section{Sample size calculation}

In a pilot study on 10 patients, we reported an intraoperative $\mathrm{P} / \mathrm{F}$ ratio of $310 \pm 32$ in morbidly obese patients undergoing bariatric operations. Using MedCalc Software 
version 14.10.2 (MedCalc Sofware bvba, Ostend, Belgium), we calculated a conservative sample size that could detect $10 \%$ difference in $\mathrm{P} / \mathrm{F}$ ratio (i.e. 31 ) between the two study groups. A minimum number of 36 patients (18 patients per group) was calculated to have a study power of $80 \%$ and alpha error of 0.05 . The number was increased to 41 patients (21 patients per group) to compensate for possible drop-outs.

\section{Statistical analysis}

Statistical package for social science (SPSS) software, version 15 for Microsoft Windows (SPSS inc., Chicago, iL, USA) was used for data analysis. Categorical data (incidences of complications and comorbidities) were presented as frequency (\%) and analysed by chi square test. Continuous data were checked for normality using Shapiro-Wilk test and was presented as mean (standard deviation) or median (interquartile range) as appropriate. Continuous data (PF ratio, compliance, dead space, age, blood loss, etc) were analysed using unpaired t test or Mann Whitney as appropriate. Repeated measures (blood pressure, heart rate, plateau pressure) were analysed using analysis of variance (ANOVA) for repeated measures with post-hoc pairwise comparisons using the Boneferroni test. A $P$ value less than 0.05 was considered statistically significant.

\section{Results}

Forty-two patients were available for final analysis (Fig. 1). Demographic data and baseline characteristics were comparable between both study groups (Table 1). Pre-operative pulmonary functions were also comparable between the two study groups (Table 1). At $90 \mathrm{~min}$, there was significant improvement in both $\mathrm{P} / \mathrm{F}$ ratio and lung compliance within dexmedetomidine group compared to the baseline reading. $\Delta \mathrm{P} / \mathrm{F}$ ratio was significantly higher in dexmedetomidine group compared to control group $\{32$ (43) $\mathrm{mmHg}$ versus -2 (60) $\mathrm{mmHg}, P=0.046$ ) (Table 2).

Compared to control group, dexmedetomidine group showed higher dynamic lung compliance at both $45 \mathrm{~min}\left\{41.3\right.$ (8) $\mathrm{mL} \mathrm{cmH}_{2} \mathrm{O}^{-1}$ Vs 34.6 (5) $\mathrm{mL}$ $\left.\mathrm{cmH}_{2} \mathrm{O}^{-1}, P=0.004\right\}$, and $90 \min \left\{44.5\right.$ (9) $\mathrm{mL} \mathrm{cmH}_{2} \mathrm{O}^{-1}$

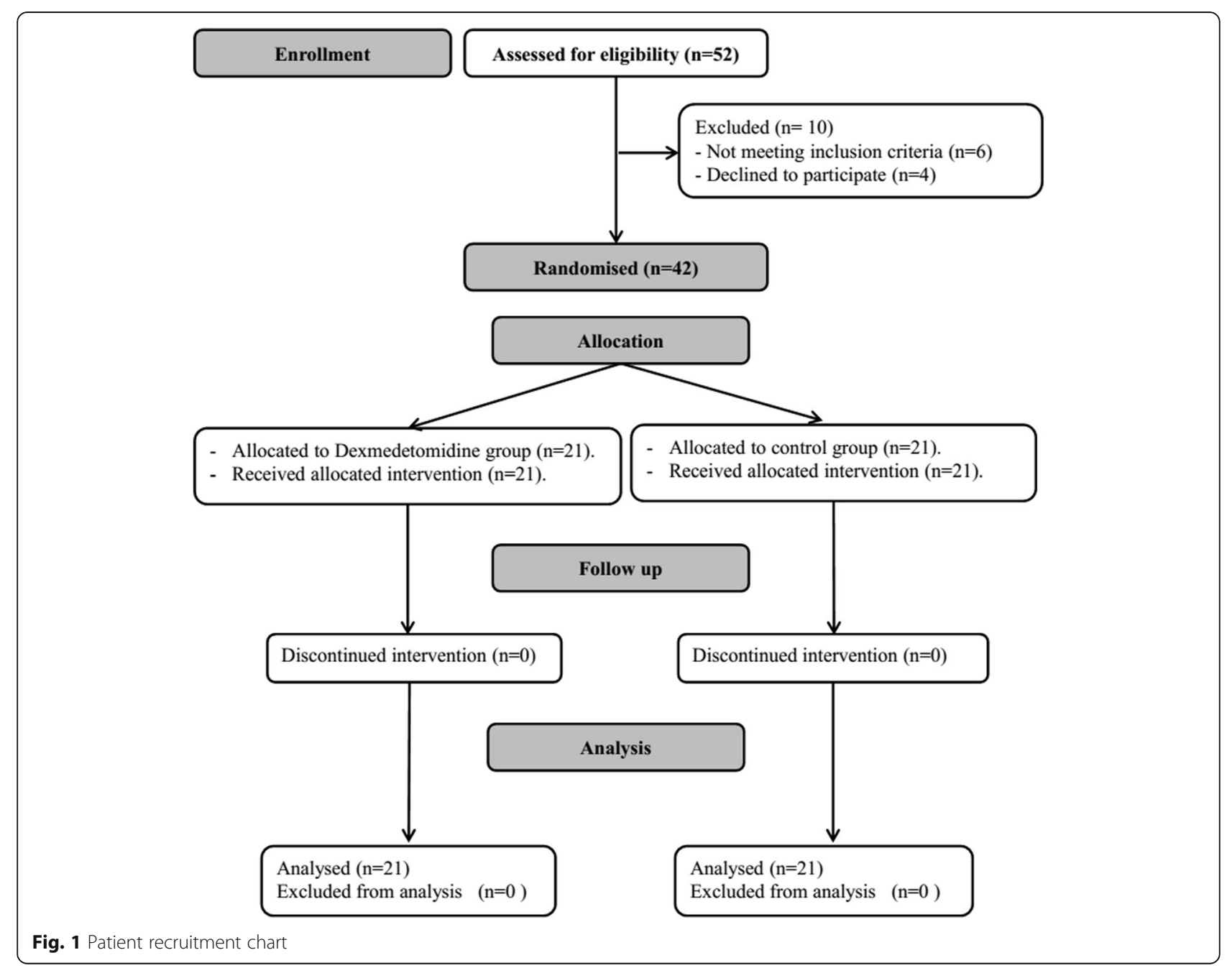


Table 1 Demographic data, baseline characteristics, and patient outcomes. Data are presented as mean (standard deviation), median (quartiles), and frequency (\%)

\begin{tabular}{|c|c|c|c|}
\hline & Control group $(n=21)$ & Dexmedetomidine group $(n=21)$ & $P$ value \\
\hline Age (years) & $32(5)^{a}$ & $29(4)$ & 0.05 \\
\hline $\mathrm{BMI}\left(\mathrm{kg} / \mathrm{m}^{2}\right)$ & $45(3)^{a}$ & $48(4)$ & 0.03 \\
\hline Smoking & $5(25 \%)$ & $6(29 \%)$ & 0.95 \\
\hline COPD, emphysema & $0(\%)$ & $0(0 \%)$ & 1 \\
\hline FVC (\% predicted) & $65(61,67)$ & $62(60,66)$ & 0.28 \\
\hline FEV1/FVC (\%) & $81(78,84)$ & $80(77,83)$ & 0.33 \\
\hline Baseline $\mathrm{PaCO}_{2}(\mathrm{mmHg})$ & $42(7)$ & $39(5)$ & 0.1 \\
\hline Surgical duration & $113(19)$ & $109(18)$ & 0.5 \\
\hline Intraoperative fluids & $844(101)$ & $831(103)$ & 0.7 \\
\hline Blood loss & $238(76)$ & $258(78)$ & 0.4 \\
\hline \multicolumn{4}{|l|}{ Postoperative complications } \\
\hline - ICU admission & $3(14 \%)$ & $2(10 \%)$ & 0.9 \\
\hline - Invasive ventilation & $2(10 \%)$ & $1(5 \%)$ & 1 \\
\hline - Anastomotic leakage & $0(0 \%)$ & $0(0 \%)$ & 1 \\
\hline - Bleeding & $0(0 \%)$ & $0(0 \%)$ & 1 \\
\hline - Pneumonia & $0(0 \%)$ & $0(0 \%)$ & 1 \\
\hline - 28-day death & $0(0 \%)$ & $0(0 \%)$ & 1 \\
\hline POSS & $2(1,2)$ & $2(1,2)$ & 1 \\
\hline
\end{tabular}

$B M I$ Body mass index, COPD Chronic obstructive pulmonary disease, FEV1 Forced expiratory volume in the first second, FVC Forced vital capacity, ICU intensive care unit, POSS Pasero opioid-induced sedation scale, P/F ratio PaO2/fraction of inspired oxygen

${ }^{a}$ denotes statistical significance between both groups

Vs 34.5 (6) $\left.\mathrm{mL} \mathrm{cmH}_{2} \mathrm{O}^{-1}, P<0.001\right\}$, in addition to higher $\Delta$ dynamic lung compliance $\left\{4\right.$ (4) $\mathrm{mL} \mathrm{cmH}_{2} \mathrm{O}^{-1}$ versus -1 (4) $\left.\mathrm{mL} \mathrm{cmH}_{2} \mathrm{O}^{-1}, P=0<0.001\right\}$ (Table 2). Static lung compliance was higher in dexmedetomidine group compared to control group at $90 \mathrm{~min}\left\{54\right.$ (13) $\mathrm{mL} \mathrm{cmH}_{2} \mathrm{O}^{-1}$ Vs 45 (11) $\mathrm{mL} \mathrm{cmH}_{2} \mathrm{O}^{-1}, P=0.01$; whilst, both groups showed comparable static lung compliance at other time points (Table 2).

Dead space significantly increased in the control group at $45 \mathrm{~min}$ and $90 \mathrm{~min}$ compared to the baseline; whilst, dead space decreased in dexmedetomidine group at 90 min compared to the baseline measurement and to the control group (Table 2). $\Delta$ dead space (\%) was significantly lower in Dexmedetomidine group compared to control group $\{-1.6(-8,1.5) \%$ Vs $3.4(0.3,6.5) \%$, $P=0.01\}$ (Table 2). Plateau pressure was lower in dexmedetomidine group compared to the control group at most measurements (Fig. 2).

Both SBP and DBP were lower in dexmedetomidine group compared to control group and compared to the baseline in most measurements (Fig. 3). Heart rate was also lower in Dexmedetomidine group compared to control group at $15 \mathrm{~min}$, and to the baseline at 60, 75, 90, and 105 min (Fig. 4).

\section{Discussion}

Dexmedetomidine infusion improved oxygenation and lung mechanics in morbidly obese patients with restrictive lung disease. Dexmedetomidine group showed higher $\mathrm{P} / \mathrm{F}$ ratio, higher compliance, lower dead space, and lower plateau pressure compared to control group.

The evidence on the possible mechanism of the favourable respiratory effects of dexmedetomidine is not clear; however various mechanisms might contribute in these effects. Animal studies reported that dexmedetomidine has a bronchodilator effect in histamine-mediated bronchospasm [1]. Dexmedetomidine was reported to preserve the hypoxic pulmonary vasoconstriction from the inhibitory effect of inhalational anesthetic agents [10], increase the perfusion of ventilated lungs [10], reduce the oxidative stress [11], and increase nitric oxide $(\mathrm{NO})[11,12]$ during OLV. Dexmedetomidine enhances hypoxic pulmonary vasoconstriction through stimulation of alpha-2B receptors in vascular smooth muscles; thus, it would improve ventilation/perfusion ratio and consequently improve oxygenation [12]. As it increases the NO level in blood, dexmedetomidine reduces intrapulmonary shunt [12]. Down regulation of various inflammatory mediators might contribute to the protective respiratory effects of dexmedetomidine [13, 14]; however, this assumption needs further evaluation in more studies because we did not measure these mediators in our patients. The potential better sedation state with dexmedetomidine administration might also contribute for improvement of lung mechanics due to better relaxation of the chest wall. 
Table 2 Lung mechanics and gas-exchange data. Data are presented as mean (standard deviation) and median (quartiles)

\begin{tabular}{|c|c|c|c|}
\hline & Control group $(n=21)$ & Dexmedetomidine group $(n=21)$ & $P$ value \\
\hline \multicolumn{4}{|l|}{$\mathrm{P} / \mathrm{F}$ ratio } \\
\hline - Baseline & $-305(68)$ & $-298(52)$ & -0.7 \\
\hline$-45 \min$ & $-300(45)$ & - $305(54)$ & -0.7 \\
\hline$-90 \mathrm{~min}$ & - $303(59)$ & $-330(61)^{b}$ & -0.2 \\
\hline - Delta P/F ratio & $--2(60)^{a}$ & $-32(43)$ & -0.046 \\
\hline \multicolumn{4}{|c|}{ Dynamic compliance $\left(\mathrm{mL} \mathrm{cmH}_{2} \mathrm{O}^{-1}\right)$} \\
\hline - Baseline & $-35.6(7)$ & $-40(9)$ & -0.07 \\
\hline$-45 \min$ & $-34.6(5)^{a}$ & $-41.3(8)$ & -0.004 \\
\hline$-90 \min$ & $-34.5(6)^{a}$ & $-44.5(9)^{b}$ & $-<0.001$ \\
\hline - Delta compliance & $--1(4)^{a}$ & $-4(4)$ & $-<0.001$ \\
\hline \multicolumn{4}{|c|}{ Static compliance $\left(\mathrm{mL} \mathrm{cmH}_{2} \mathrm{O}^{-1}\right)$} \\
\hline - Baseline & $-45(12)$ & $-51(14)$ & -0.14 \\
\hline$-45 \min$ & $-44(9)$ & $-51(12)$ & -0.057 \\
\hline$-90 \min$ & $-45(11)^{a}$ & $-54(13)$ & -0.01 \\
\hline - Delta compliance & $--0.7(7)$ & $-3(8)$ & -0.1 \\
\hline \multicolumn{4}{|l|}{ Dead space (\%) } \\
\hline - Baseline & $-18(6)$ & $-20(8)$ & -0.3 \\
\hline$-45 \min$ & $-21(8)^{b}$ & $-19(6)$ & -0.4 \\
\hline$-90 \min$ & $-22(8)^{a, b}$ & $-17(5)^{b}$ & -0.02 \\
\hline - Delta dead-space \% & $-3.4(0.3,6.5)^{a}$ & $--1.6(-8,1.5)$ & -0.01 \\
\hline \multicolumn{4}{|l|}{$\mathrm{PaCO}_{2}(\mathrm{mmHg})$} \\
\hline - Baseline & $-42.3(7)$ & $-39.5(5)$ & -0.1 \\
\hline$-45 \min$ & $-45.7(7)^{b}$ & $-42(7)^{b}$ & -0.08 \\
\hline$-90 \min$ & $-46.8(6)^{b}$ & $-43(7)^{b}$ & -0.052 \\
\hline - Delta $\mathrm{PaCO}_{2}$ & $--4.4(6)$ & $--3.5(6)$ & -0.6 \\
\hline
\end{tabular}

$\mathrm{P} / \mathrm{F}$ ratio: $\mathrm{PaO} 2 /$ fraction of inspired oxygen. Delta: 90 -min measurement - baseline measurement

adenotes statistical significance between both groups

bdenotes statistical significance compared to the baseline reading within the same group

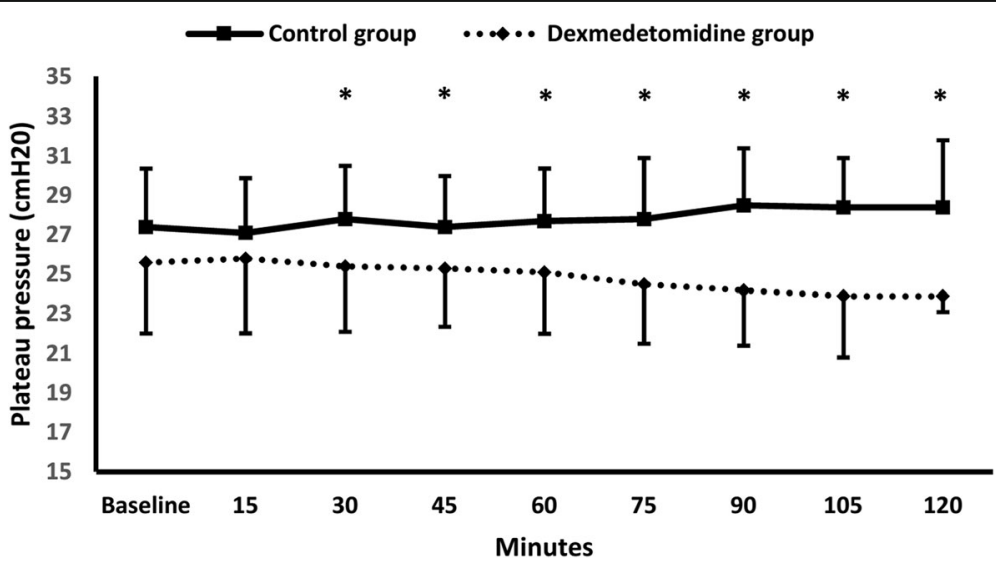

Fig. 2 Plateau pressure. * denotes significance between both groups 


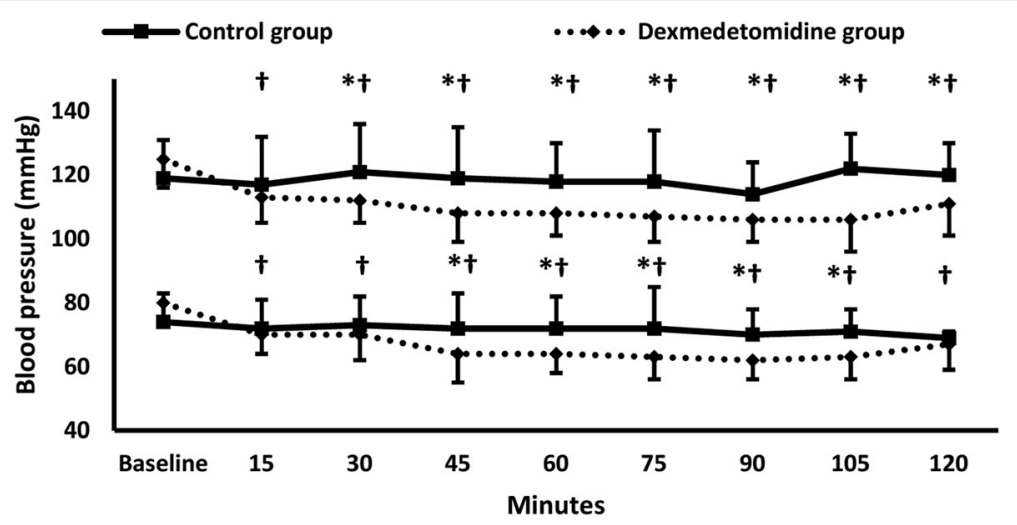

Fig. 3 Systolic and diastolic blood pressure. ${ }^{*}$ denotes significance between both groups, $\dagger$ denotes significance compared to the baseline reading within dexmedetomidine group

When used as a sedative agent, dexmedetomidine resulted in better patient-ventilator synchrony [15] and more ventilator free hours [16] in critically ill adults. Dexmedetomidine had shortened the weaning process in critically ill children [17]. Dexmedetomidine improved oxygenation and lung mechanics during OLV in thoracic surgery $[10,12]$ and in COPD patients undergoing lung cancer surgery [3]. Dexmedetomidine had a protective effect against independent lung injury during OLV [13]. Dexmedetomidine improved alveolar oxygenation when used for induction of anesthesia in children with tetralogy of Fallot [18]. In restrictive lung diseases, the available data were extracted from animal studies. Compared to Propofol, dexmedetomidine administration resulted in better lung characteristics in rats with experimental obesity [4]. Dexmedetomidine had a protective effect lipopolysaccharide-induced lung injury rats $[14,19]$. To the best of our knowledge, this study is the first to investigate the effect of dexmedetomidine on oxygenation and lung mechanics in patients with restrictive lung disease.
According to the baseline characteristics, all our patients showed isolated pattern of restrictive lung disease without the evidence of obstructive pattern. Thus, our findings declare a relatively novel effect of dexmedetomidine infusion on respiratory mechanics in the population of morbidly obese patients with restrictive lung disease. This effect was not previously reported in humans. The favourable effects for dexmedetomidine on oxygenation and lung mechanics in our patients were moderate; we reported an improvement of nearly $10 \%$ in the $\mathrm{P} / \mathrm{F}$ ratio after $90-\mathrm{min}$ dexmedetomidine infusion. Lee et al. had reported similar improvement in oxygenation and lung mechanics in COPD patients undergoing lung cancer surgery [3]. Longer duration (and/or higher doses) might result in more significant results. Moreover, this moderate improvement might be of higher value in patients with compromised respiratory status in operating room and intensive care unit. However, this assumption need to be confirmed by randomized controlled trials.

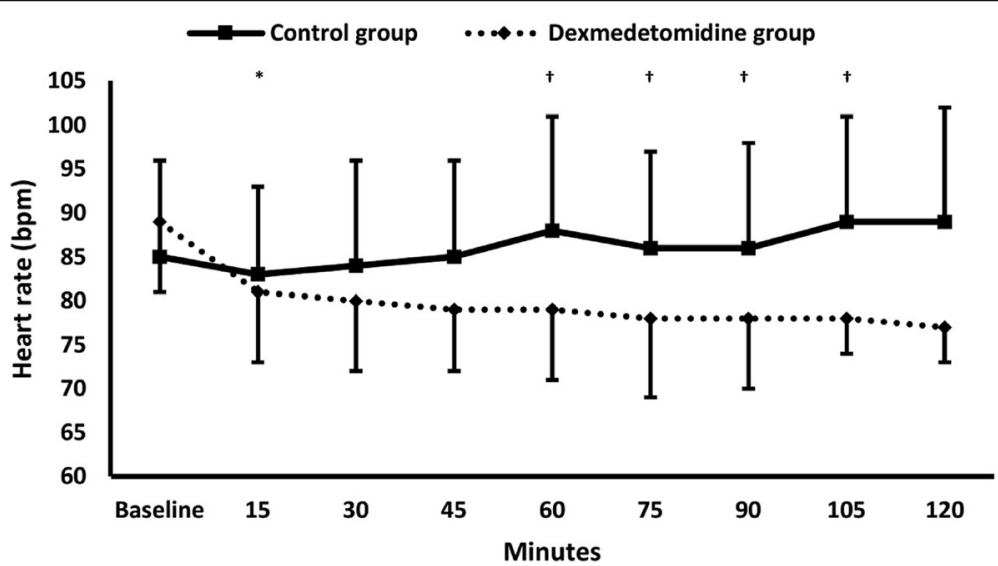

Fig. 4 Heart rate. ${ }^{*}$ denotes significance between both groups, $†$ denotes significance compared to the baseline reading within dexmedetomidine group 
Only five of our patients (12\%) experienced postoperative hypoxia in the PACU that needed ICU admission. Although there was no significant difference between both study groups regarding postoperative ICU need, we could not generalize this finding because our study was not powered enough to judge it.

\section{Study limitations}

Our study had some limitations. First: we used only one dose of dexmedetomidine for $90 \mathrm{~min}$. This was because we considered our study as an exploratory study for the effect of dexmedetomidine in this population. Based on our results, we recommend more studies to investigate whether these effects could differ with different doses and with longer infusion duration. Second: the use of Hardman \& Aitkenhead equation for calculation of physiological dead space; this was because volumetric capnography was not available in our unit. Third: We did not use lung recruitment manoeuvres; this was based what Defresne et al. had reported in morbidly obese patients during laparoscopic gastric bypass surgery [20].

\section{Conclusion}

A 90-min dexmedetomidine infusion resulted in moderate improvement in oxygenation and lung mechanics in morbidly obese patients with restrictive lung disease.

\begin{abstract}
Abbreviations
ANOVA: Analysis of variance; BMl: Body mass index; COPD: Chronic obstructive pulmonary disease; DBP: Diastolic blood pressure; ECG: Electrocardiography; EtCO2: End-tidal carbon dioxide; FEV1: Forced expiratory volume in the first second; FVC: Forced vital capacity; NO: Nitric oxide; OLV: One lung ventilation; $\mathrm{P} / \mathrm{F}$ ratio: $\mathrm{PaO}_{2} /$ Fraction of inspired oxygen; PaCO2: Pressure of arterial carbon dioxide; PACU: Post anaesthesia care unit; $\mathrm{PaO}_{2}$ : Pressure of arterial oxygen; PEEP: Positive end expiratory pressure; SBP: Systolic blood pressure; SPSS: Statistical package for social science
\end{abstract}

\section{Acknowledgements}

We would thank Dr. Menna Alshaarawy, resident of anesthesia, Cairo University for her help in this work.

\section{Funding}

Cairo university hospitals.

\section{Availability of data and materials}

The data that support the findings of this study are available from Cairo university hospitals; however, they are not publicly available. Data are however available from the authors upon reasonable request after permission of Cairo university.

\section{Authors' contributions}

$\mathrm{AH}$ was responsible for the conception and design of the study, analysis of the data, and writing the manuscript. KT, BA, AA, ME, and AR shared in data collection. SA, MM, and $\mathrm{HO}$ made substantial contribution in the design of the study, writing and revising the manuscript. $A H, K T, B A, A A, M E, A R, S M A$, SW, HO, MM and YA shared in writing and revising the manuscript. All authors had read, revised and approved the final manuscript.

\section{Ethics approval and consent to participate}

Ethical approval from Cairo university hospitals research committee was obtained (N-12-2016). Written informed consents were obtained from participants before inclusion.
Consent for publication

Not applicable.

\section{Competing interests}

The authors declare that they have no competing interests.

\section{Publisher's Note}

Springer Nature remains neutral with regard to jurisdictional claims in published maps and institutional affiliations.

Received: 7 April 2018 Accepted: 1 August 2018

Published online: 14 August 2018

References

1. Groeben H, Mitzner W, Brown RH. Effects of the alpha2-adrenoceptor agonist dexmedetomidine on bronchoconstriction in dogs. Anesthesiology. 2004;100:359-63.

2. Unal Y, Pampal HK, Arslan M, Demirel CB, Alkan M. The effects of dexmedetomidine on pulmonary artery pressure in experiment. Bratisl Lek ListyBratisl Lek Listy. 2014;115:272-4.

3. Lee SH, Kim N, Lee CY, Ban MG, Oh YJ. Effects of dexmedetomidine on oxygenation and lung mechanics in patients with moderate chronic obstructive pulmonary disease undergoing lung cancer surgery. Eur J Anaesthesiol. 2016:33:1-8.

4. Heil LBB, Santos CL, Santos RS, et al. The effects of short-term Propofol and Dexmedetomidine on lung mechanics, histology, and biological markers in experimental obesity. Anesth Analg. 2016;122:1015-23.

5. Ortiz VE, Kwo J. Obesity: physiologic changes and implications for preoperative management. BMC Anesthesiol. 2015;15:97.

6. De Baerdemaeker L, Margarson M. Best anaesthetic drug strategy for morbidly obese patients. Curr Opin Anaesthesiol. 2015;29:119-28.

7. Fernandez-Bustamante A, Hashimoto S, Serpa Neto A, Moine P, Vidal Melo MF, Repine JE. Perioperative lung protective ventilation in obese patients. BMC Anesthesiol. 2015;15:56.

8. Hardman JG, Aitkenhead AR. Estimating alveolar dead space from the arterial to end-tidal CO (2) gradient: a modeling analysis. Anesth Analg. 2003;97:1846-51.

9. Kobelt P, Burke K, Renker P. Evaluation of a standardized sedation assessment for opioid Administration in the Post Anesthesia Care Unit. Pain Manag Nurs. 2014;15:672-81.

10. Xia R, Yin H, Xia Z, Mao Q, Chen G, Xu W. Effect of intravenous infusion of dexmedetomidine combined with inhalation of isoflurane on arterial oxygenation and intrapulmonary shunt during single-lung ventilation. Cell Biochem Biophys. 2013;67:1547-50.

11. Xia $R, X u J$, Yin $H$, et al. Intravenous infusion of Dexmedetomidine combined isoflurane inhalation reduces oxidative stress and potentiates hypoxia pulmonary vasoconstriction during one-lung ventilation in patients. Mediat Inflamm. 2015;2015:238041.

12. Huang S-Q, Zhang J, Zhang X-X, et al. Can Dexmedetomidine Improve Arterial Oxygenation and Intrapulmonary Shunt during One-lung Ventilation in Adults Undergoing Thoracic Surgery? A Meta-analysis of Randomized, Placebo-controlled Trials. Chin Med J. 2017;130:1707.

13. Zhang W, Zhang S, Li B, Sun M, Zhang J. Paravertebral dexmedetomidine as an adjuvant to ropivacaine protects against independent lung injury during one-lung ventilation: a preliminary randomized clinical trial. BMC Anesthesiol. 2018;18:67.

14. Meng L, Li L, LU S, et al. The protective effect of dexmedetomidine on LPSinduced acute lung injury through the HMGB1-mediated TLR4/NF-KB and PI3K/Akt/mTOR pathways. Mol Immunol. 2018:94:7-17.

15. Conti G, Ranieri VM, Costa R, et al. Effects of dexmedetomidine and propofol on patient-ventilator interaction in difficult-to-wean, mechanically ventilated patients: a prospective, open-label, randomised, multicentre study. Crit Care. 2016;20:206.

16. Reade MC, Eastwood GM, Bellomo R, et al. Effect of Dexmedetomidine added to standard care on ventilator-free time in patients with agitated delirium: a randomized clinical trial. JAMA. 2016:315:1460-8.

17. Grant MJC, Schneider JB, Asaro LA, et al. Dexmedetomidine use in critically ill children with acute respiratory failure. Pediatr Crit Care Med. 2016;17:1131-41. 
18. Gu H, Bai J, Liu J. Effects of dexmedetomidine versus propofol on SPO2 in children with tetralogy of fallot during anesthesia. Int J Clin Exp Med. 2015; 8:22550-6.

19. Meng PZ, Liu J, Hu PS, Tong F. Protective effect of Dexmedetomidine on endotoxin-induced acute lung injury in rats. Med Sci Monit. 2018;24: 4869-75.

20. Defresne AA, Hans GA, Goffin PJ, et al. Recruitment of lung volume during surgery neither affects the postoperative spirometry nor the risk of

hypoxaemia after laparoscopic gastric bypass in morbidly obese patients: a randomized controlled study. Br J Anaesth. 2014;113:501-7.

Ready to submit your research? Choose BMC and benefit from:

- fast, convenient online submission

- thorough peer review by experienced researchers in your field

- rapid publication on acceptance

- support for research data, including large and complex data types

- gold Open Access which fosters wider collaboration and increased citations

- maximum visibility for your research: over $100 \mathrm{M}$ website views per year

At BMC, research is always in progress.

Learn more biomedcentral.com/submissions 